\title{
Reply to the Letter to the Editor "Does Remifentanil Have a Place for Sedation in the Case of Endotracheal Intubation or Minimally Invasive Surfactant Therapy in Neonates?"
}

\author{
Ellen H.M. de Kort ${ }^{\mathrm{a}}$ b Sinno H.P. Simons ${ }^{\mathrm{b}}$

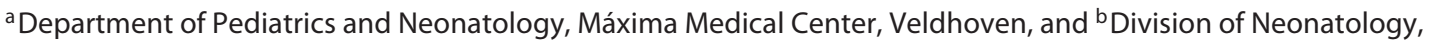 \\ Department of Pediatrics, Erasmus MC-Sophia Children's Hospital, Rotterdam, The Netherlands
}

Dear Sir,

We welcome the interest shown by Chollat et al. [1] in our article on remifentanil as an induction agent for the INSURE procedure in preterm neonates [2]. We thank the authors for their critical feedback from their experience in the field. Based on our own experience and on the available literature, we would like to comment on some of these critical comments.

The authors state that remifentanil has become an agent used for sedation and analgesia for tracheal intubation or minimally invasive surfactant therapy (MIST). Over the past decade several articles have appeared in the literature on the use of remifentanil for endotracheal intubation, either as sole medication or in combination with other drugs [3-6]. Also, one article studied the effect of remifentanil during the Intubation-SURfactant-Extubation procedure [7]. However, to the best of our knowledge no studies have yet appeared in the literature investigating the efficacy and safety of remifentanil during MIST.

We studied the efficacy and safety of remifentanil during INSURE [2]. In their comment Chollat et al. [1] refer to the MIST procedure on several occasions. We would like to point out that INSURE and MIST are different procedures. During INSURE an endotracheal tube is placed and invasive ventilation is applied for a short period of time. Although recovery of the respiratory drive should be quick, completely maintaining the respiratory drive is less important. MIST was developed to prevent any artificial ventilation during surfactant administration. While the patient is spontaneously breathing on noninvasive respiratory support, a small catheter is placed through the vocal cords and surfactant is administered. So maintaining a sufficient respiratory drive is a key element in the MIST procedure. These different principles could warrant different levels of sedation.

According to the authors it seems inappropriate to reach a stage of general anesthesia using an opioid alone. We completely agree with this statement. The purpose of administering premedication before endotracheal intubation, also for the INSURE procedure, should be to reach a level of sedation and analgesia enough to blunt the stress response, reduce the physiological abnormalities that can accompany this stress response, facilitate the procedure, and reduce the potential for airway injury [8-13]. In order to achieve these goals, a certain level of sedation should be achieved. There is no uniform definition of sufficient sedation before intubation and there are no validated methods to measure the degree of sedation. The sedation score we used should, in our opinion, adequately reflect the degree of sedation necessary to achieve the goals of premedication before endotracheal intubation. However, this score is yet to be validated.

Studies that evaluated remifentanil as single agent before endotracheal intubation used doses ranging from 1 to $3 \mu \mathrm{g} / \mathrm{kg}$ $[3-5,7]$. Chollat et al. [1] concluded that the doses used in these studies provided a good quality of sedation. These studies did indeed find no significant differences in the total duration of intubation time and the number of attempts for successful intubation between the remifentanil group and the control groups. Unfortunately, no difference between remifentanil and other combinations of drugs does not indisputably indicate adequate sedation in the remifentanil group. It can just as well mean

\section{KARGER}

(C) 2017 S. Karger AG, Base
Ellen H.M. de Kort

Department of Pediatrics and Neonatology Máxima Medical Center, De Run 4600 NL-5504 DB Veldhoven (The Netherlands) E-Mail e.dekort@mmc.nl 
that the sedation is as bad as in the control groups. All studies do not explicitly report on the quality of sedation.

Several other parameters can give an indication about the quality of sedation, for example, the number of attempts and intubation conditions. In the study by Choong et al. [3] using $3 \mu \mathrm{g} / \mathrm{kg}$ of remifentanil in $60 \mathrm{~s}$, self-reported intubation conditions rated by the intubator on a 7-point Likert scale were fair to poor in $25 \%$ of cases. Besides this, 3 patients received additional succinylcholine for reasons other than chest wall rigidity. Avino et al. [4] administered $1 \mu \mathrm{g} / \mathrm{kg}$ remifentanil in $60 \mathrm{~s}$ and intubation conditions were poor in $31 \%$ of patients. Also, 4 patients were excluded from the analysis because they needed more than 2 intubation attempts. Although there could be other explanations, these data could also reflect an insufficient degree of sedation. Only Welzing et al. [7], evaluating remifentanil during INSURE, reported excellent or good intubation conditions in all patients. Although $29 \%$ of patients needed a second intubation attempt, the authors mentioned that inadequate sedation was never the reason for failed attempts.

Taking this into consideration, the ineffectiveness of remifentanil in our study seems to possibly be in contrast with these previous studies. Chollat et al. [1] suggest that a short time frame to allow for drug effect could be the possible cause. As described in the methods section of our report, the sedation score was performed after remifentanil infusion and if inadequate, the score was repeated after 30-60 s, before a subsequent dose was administered. This leads to an interval between remifentanil doses of about $90-120 \mathrm{~s}$, enough to allow for drug effect based on the known fast onset of action of remifentanil.

Remifentanil has a rapid onset and end of action, and almost immediate recovery of the clinical effect after interruption of administration. Thus, it has a short context-specific half-life with a short elimination time that is not influenced by the infusion time with no cumulative effects [14]. Based on these pharmacokinetic character- istics, assuming cumulative dosing in patients receiving multiple doses seems inappropriate, and each dose should be accounted for on its own. Even if speaking of cumulative dosing should be justified, the cumulative doses used in our study are not that much higher than those used in previous studies administering a single dose [3$5,7]$.

Finally, we would like to briefly address the issue of chest wall rigidity. We definitively agree with Chollat et al. [1] that the incidence of chest wall rigidity in our study was much higher than in previous studies. We attribute this higher incidence completely to the fast infusion rate of remifentanil we used in our study, which was twice as fast as in previous studies. Therefore, in our opinion it is justified to hold on to our conclusion that with an infusion rate of $30 \mathrm{~s}$, remifentanil carries an unacceptable high risk of side effects. We do agree that when using slower infusion rates, remifentanil seems to be much safer. We also agree that remifentanil might be a feasible drug for INSURE or MIST, if used appropriately.

\section{References}

1 Chollat C, Tourrel F, Marret S: Does remifentanil have a place for sedation in the case of endotracheal intubation or minimally invasive surfactant therapy in neonates? Neonatology 2017;112:372-373.

$\checkmark 2$ de Kort EHM, Hanff LM, Roofthooft D, Reiss IKM, Simons SHP: Insufficient sedation and severe side effects after fast administration of remifentanil during INSURE in preterm newborns. Neonatology 2017;111:172-176.

-3 Choong K, Alfaleh K, Doucette J, Gray S, Rich B, Verhey L, Paes B: Remifentanil for endotracheal intubation in neonates: a randomized controlled trial. Arch Dis Child Fetal Neonatal Ed 2010;95:F80-F84.

-4 Avino D, Zhang WH, De Ville A, Johansson $\mathrm{AB}$ : Remifentanil versus morphine-midazolam premedication on the quality of endotracheal intubation in neonates: a non-inferiority randomized trial. J Pediatr 2014;164 1032-1037.
Badiee Z, Vakiliamini M, Mohammedizadeh M: Remifentanil for endotracheal intubation in premature infants: a randomized controlled trial. J Res Pharm Pract 2013;2:75-82.

$\checkmark 6$ Pereira e Silva Y, Gomez RG, Marcatto J, Maximo TA, Barbosa RF, Simões e Silva AC: Morphine versus remifentanil for intubating preterm neonates. Arch Dis Child Fetal Neonatal Ed 2007;92:F293-F294.

7 Welzing L, Kribs A, Huenseler C, Eifinger F, Mehler K, Roth B: Remifentanil for INSURE in preterm infants: a pilot study for evaluation of efficacy and safety aspects. Acta Paediatr 2009;98:1416-1420.

$>8$ Buthada A, Sahni R, Rastogi S, Wung JT: Randomised controlled trial of thiopental for intubation in neonates. Arch Dis Child Fetal Neonatal Ed 2000;82:F34-F37.

$\checkmark 9$ Oei J, Hari R, Butha T, Lui K: Facilitation of neonatal nasotracheal intubation with premedication: a randomized controlled trial. J Paediatr Child Health 2002;38:146-150.
$>10$ Barrington KJ, Finer NN, Etches PC: Succinylcholine and atropine for premedication of the newborn infant before nasotracheal intubation: a randomized, controlled trial. Crit Care Med 1989;17:1293-1296.

$>11$ Carbajal R, Eble B, Anand KJS: Premedication for tracheal intubation in neonates: confusion or controversy? Semin Perinatol 2007;31: 309-317.

12 Kumar P, Denson SE, Mancuso TJ, et.al: Premedication for nonemergency endotracheal intubation in the neonate. Pediatrics 2010; 125:608-615.

-13 Byrne E, MacKinnon R: Should premedication be used for semi-urgent or elective intubation in neonates? Arch Dis Child 2006;91: 79-83.

14 Penido MG, Garaa R, Sammartino M, Pereira e Silva Y: Remifentanil in neonatal intensive care and anaesthesia practice. Acta Paediatr 2010;99:1454-1463.
Sedation by Remifentanil in Neonates: Reply
Neonatology 2017;112:374-375 DOI: $10.1159 / 000479623$ 